\title{
Humour and laughter as vestiges of evolution
}

\author{
Amadeu Viana \\ Universitat de Lleida, Catalonia, Spain \\ aviana@filcat.udl.cat
}

\begin{abstract}
This paper argues in favour of considering humour and laughter as embodied signs of the ancient, sympathetic, figurative mode of the human mind, still working with us in dance, music, singing and literary activity. Starting from steady evolutionary provisos, both the continuity and the departing lines between nonhuman vocalisations and human laughter are considered. Along the Duchenne and non-Duchenne expression types, we analyse the developmental extension of laughter, both social and cognitive, probably under complex imitative forms through millennia until the emergence of articulated languages. Then, we try to explain the particular attachment of humour and laughter to evolutionary achievements in the symbolic domain. Thus, from a cognitive and semiotic framework, here it is argued that the old signal of play and joy might have evolved on a par with full connectivity and unbounded associations promoted by symbolic activity, clinging to new meanings and abilities, but still governed by the conjoined social work of sanction and solidarity, a pattern that humour shows all over around. As a particular reflex of ancient multimodality, laughter (with humour) seems akin to participative, mythical modes of thinking that were in full force and effect at the beginning of human societies, rooted in metaphors and figurativeness. Since both humour and laughter still find their way in the contemporary contexts of free associations, human projections and extended agentivity, they could be properly considered as the embodied, old counterpart of the imaginative dimension of symbolic activity.
\end{abstract}

Keywords: evolution, mind, laughter, semiotics, figurativeness.

\section{Introduction}

The purpose of this study is to explore the idea that both laughter and humour can be viewed as remnants or traces signalling the long haul of evolution of human language and mind. As far as laughter is concerned, researchers have championed its link with prelinguistic origins and primate expressions of joy and play (Deacon 1992; Provine 2000; Davila Ross et al. 2009 ; 2010). Humour, on the contrary, has been recently examined on a rationalistic basis even if evolutionary arguments enter into consideration (cf. Hurley et al. 2011). Trying to overturn this tendency, in this paper, it is argued that humour is an early manifestation of the 
imaginative function of the mind, attached to the old reflex of laughter, and so imprinted in the ancient, physical, embodied networks that compound the body and the mind.

The idea that the human mind evolved from an original, poetic and mythic stance attributing animated properties to the world, as is commonly described by anthropologists (Bateson 1972; Leach 1976), implies that clear-cut categories and logical classifications have found their way for particular actions among this primary breeding ground of metaphors, figuration and connectivity. Some of the research about the evolution of the mind assumes the consequences of considering human mind and society as produced by a long path of changes and discoveries, including the way the mind presents itself through narrative and metaphorical speech and the appearance the world takes through religion and ritual (Donald 1991; Mithen 1996). Usually, evolutionary research tends to obviate these aspects and focuses on naturalistic issues (Dunbar \& Barrett 2007) or is rightly devoted to evolutionary dilemmas (Tomasello 2014). However, from a cognitive and semiotic approach, which assumes that mind is a product and also produces content and meaning, the idea of a set of initial stages of metaphorical and figurative thinking has been fruitfully explored (Danesi 1993; Turner 1997; Wildgen 2004; Turner 2006; Zlatev 2012). Of course, as is frequently pointed out (Turner 1997; 2006), these ancient capacities remain with us, have mutated in meaningful ways and keep their creative power in dance, music, singing, literary works, cinema and new media. The ubiquity of imagination and fantasy today and its myriad of aspects and uses should not be an obstacle to consider seriously the import of figurativeness in early stages of the mind. If old myths (considered as a conjunction of literature and the sacred) are still eloquent enough, it is because they were ancient forms of order and meaning, ways of the mind to cope with the world, before (and besides) the spread of writing and the more rational attempts to understanding nature. The human mind presumably took off by overproducing signals, and thus ambiguity and figuration must be taken as crucial definitory features (Viana 2015).

The thesis of this paper tries to situate humour and laughter in the old scenery of figurativeness, connectivity and participation. Here it will be argued that humour and laughter are vestiges of early stages of hominisation, when an ancient bodily reflex surpassed its uses and readjusted to encompass social ridicule and incongruity, to finally be rewired or rerouted to highlight unlimited associations in the symbolic domain, and thus echoing the participative, figurative stages of the human mind. As Bateson (1985) remarked, the value of humour, related to insight and creativity, has kept growing as it stuck to a variety of forms of knowledge and, far from disappearing in the course of evolution and history, we nowadays find it pervading many different dimensions and domains of society. By dating it back to the old scenery, humour may be approached as a form of creativity still with us, like literature, music or dance, but unlike these manifestations, it still may be viewed as composing an overt unmistakable embodied sign in its connection with laughter.

However, there is not a one-to-one relationship between laughter and humour (Provine 2000; Chafe 2007), since laughter exceeds humour and vice versa, and so here it is methodologically assumed a) that laughter, as a prelinguistic human call, linked to play and joy, preceded symbolic activity (Deacon 1997), and b) that forms of humour, enabled by social sanction (i.e. ridicule) and incongruity, presumably developed through imitation and behavioural alignment long before the emergence of articulated languages (Gervais \& Wilson 2005). Then, it can be inferred that laughter, whose respiratory patterns were conducive to assimilating laughter and speech, and humour (via incongruity and ridicule) fruitfully coevolved with symbolic activity, although keeping their separate paths that allow us to distinguish social, imitative smiling and laughter from spontaneous outbursts of laughter, and still from humour as a cognitive dimension implying incongruity and belittlement, as we shall see in the following pages. Nevertheless, we are very conscious that in order to achieve a 
sound result on the evolutionary paths of laughter and humour more evidence is needed, and so our hypothesis must be certainly tentative, until converging evidence from other sources (i.e. developmental and gestural data, evidence from sign languages) can be found.

In order to carry our argument forward, in the following sections we examine a) laughter in evolutionary perspective, including multimodality, its coevolution with vocal calls, Duchenne \& Non-Duchenne laughter and their extension through imitation processes; b) social and cognitive issues concerning humour, as enabled by incongruity and social sanction, and its coevolution with the symbolic dimension via extended connectivity, by means of contact and similitude; and c) the structural conditions that link humour and its partially convergent bodily sign, laughter, to figurativeness, dreaming and creativity, as properties of the original mind; and their persistence and pervasiveness in the contemporary contexts of free association, human projections and extended agentivity.

\section{Evolutionary issues}

\subsection{Multimodality preceded articulated languages}

There is a certain agreement in contemporary research about the precedence and the ubiquitous role of multimodality in human evolution (Deacon 1997; Corballis 2003; Tomasello 2008; Fitch 2010). Multimodal semiotics, including a variety of vocal calls, has presumably shaped hominid life during millennia, before the quasi-autonomous forms of spoken language emerged. If we look for pragmatic and multimodal signals in everyday conversation, so the argument goes, we could grasp a little bit of how early communication, prior to autonomous linguistic skills, might have been: recall the different pointing systems, a huge variety of hand abilities (including working, counting and signing abilities), paralinguistic signals (including face interpretation), shouting and intended intonation, the social meaning of objects, clothes and commodities, iconicity and mimicry. Gestures, objects and the body have probably been the fertile land from where metaphorical and metonymical information have been extracted (Corballis 2003; Tomasello 2008). But we cannot but think that multimodality also included a variety of vocal abilities. As Deacon (1997: 355-356) has argued, although vocal skills were limited, they presumably existed side by side with gestures for almost 2 million years, and thus both dimensions are supposed to coevolve, developing complex relationships. In this respect, the pragmatically-oriented research carried out by Scott-Phillips (2014), assuming what he calls an ostensive-inferential model for the evolution of language and cognition, represents a positive contribution in order to understand how these complex levels of evolutionary integration may have worked.

The argument of coevolution tends to give support to two different phases of hominid evolution, well attested in the fossil record, from homo habilis to homo ergaster, and from homo ergaster to homo sapiens, covering a range of 2.5 million years. During the first phase, basic bipedal abilities linked to manual work are usually described, while the second phase implies more elaborated handwork, presumably social abilities, maybe singing and more functional vocal calls, an extended multimodality, hunting strategies and likely some degree of fire and dwelling expertise (Mithen 1996; Fitch 2010). The issue of singing is particularly interesting because it relates vocal skills to social, imaginative and emotional dimensions in a way that has been considered as a precursor (even, a parallel one) to articulated language competence (Mithen 2005; Fitch 2010: 466-507). If we consider laughter as a specific human call (as well as sobbing; see section 2.2), we should place its origin in continuity with early Australopithecine calls, clearly preceding more elaborate vocal abilities. 
The same degree of consensus seems to have been achieved in regard to the expansion of articulated languages, although scholars usually diverge about the impact, the pace and the circumstances under which this expansion took place (Dunbar \& Barrett 2007; Larson et al. 2010; Fitch 2010). The idea that only around the evolution of homo sapiens full articulated languages took off in Africa and outside Africa turns out to be very appealing. If it was the case, articulated languages would have grown amidst a multifarious display of calls, objects and gestures, both metonymical and metaphorical, and would have been in turn fuelled by these rich networks of multimodal activity, as cognitive semiotics maintains (Wildgen 2004; Heine \& Kuteva 2007; Viana 2015), and the pragmatically-based ostensive-inferential model has explored (Scott-Phillips 2014). It has been argued that articulated languages are a byproduct of a critical degree of brain maturation only achieved lately in the recent phases of human evolution (Balari \& Lorenzo 2013), probably related to postfetal brain growth (Barbieri 2010). If it is so, the mutual involvement between the two cognitive levels, the antique multimodal order and the new cognitive acceleration provided by articulated voices, presumably produced the spread of languages around the world and the distinct and creative configuration we currently know, that is, a full level of symbolic activity characterised by unbounded interpretation (Viana 2015).

At any rate, the imbrication between humour, laughter and human language seems nontrivial, intriguingly elaborated during the course of evolution. Laughter accompanies everyday conversation and ordinary experience, as well as humour (depending, of course, on the usual diversity of time, place and situation). Here, it is tentatively assumed that the antique call of joy and play muted and diversified in different types of smile and laughter, adopting multiple functions through imitation processes. Humour as a cognitive dimension, related to incongruity and ridicule, may have evolved along these imitative and social procedures; and, since laughter's respiratory patterns were conducive to assimilating laughter and speech, humour and laughter had presumably been rerouted to reverberate in the participative, figurative stages of the human mind, through joking and word playing, accompanying the symbolic dimension. The common approach to these topics usually comes from neo-Darwinian paradigms, insisting on the expected selective evolutionary pressures, which stress confidence and ease, the lack of inhibition and the absence of fear, an approach usually reinforced by both social and neuroscientific research (Ramachandran 1998; Scott et al. 2014). Besides these quite reliable explanations, in this paper a complementary path will be followed, more akin to bioanthropological and semiotic issues.

\subsection{Laughing and sobbing as ancient calls}

The continuity of emotional answers covering from nonhuman mammals to man, including the diversity of sounds, means and situations where they can be put to work, has attracted the attention of many scholars (Altenmüller et al. 2013). One common idea is that human bipedalism, by freeing the upper sections of the body, allowed new connections for the hands, new possibilities for the thorax and the arms, better relationships between breathing and voicing, properties that turned out to be crucial for the development of laughter, regarded from a coevolutionary framework (Provine 2000; 2016). In this respect, laughing as well as sobbing have been considered as the remnants of antique human calls, related to these new breathing possibilities. It has even been suggested that there might have existed a wider range of human calls which were lost today, after the potentialities opened by articulated languages (Deacon 1992). Considered in a wide sense, breathing and its variations are deemed as the first semi voluntary signals pretty distinctive of the human species. Shouts, screams, howls, yells, whistles, moans, groans, and so on, indicate the variegated meanings we attribute to breathing possibilities, not to mention the case of historical associations 
created in many language families around the semantic field of breathing, associated with the mind, the soul or the spiritual life; and, of course, the more subtle references to whisper, mutter or blowing, counting all these as foundations of meaning. As Deacon (1997: 234) puts it, "[c] hanges in respiration patterns provide some of the most useful indices of arousal state. Accentuating the symptoms of respiration by making a hissing sound [...] may have provided some of the earliest forms of vocal communication". The growth and complexity of paralinguistic signals, those jointed signs which usually comprise some gesture display, a particular facial disposition, some voiced or unvoiced sound (i.e. the concourse of systemic multimodality) should have been relevant features during the many millennia that antedated homo sapiens.

Laughter is not a minor issue in this respect. Interesting research has been conducted related to the differences between voiced and non-voiced laughter in different contexts (Bachorowski \& Owren 2001), demonstrating that the antique breathing pattern and its consequences are still in use. The argument on the continuity between nonhuman mammals and modern humans happens to be of special interest when laughter is reckoned. As Provine (2000: 75-84) remarked, common primate laughter functions in the two senses, inhaling as well as exhaling: it consists of continuous inspire-expire bursts, more or less voiced according to different tones and rhythms. Human laughter, on the contrary, normally functions only in one way, that of exhaling. The comparison with its breathing inverted counterpart is meaningful: human sobbing functions by inhaling, as we all know well from the exaggerated sighs of children after crying. Deacon (1997: 419) described the opposite, complementary respiratory pattern of laughing and sobbing, remarked their emergency and extension during the first years of life, before full linguistic activity, and their contagiousness mainly in first infancy (laughter keeps being contagious during the whole adult life). These features qualify laughter and sobbing as manifestations of innate calls in hominids, ruled by early visceral control over emotions (non full-voluntary), as opposed to cortical control (fullvoluntary), as it happens to be with human speech. The most interesting question here is that human speech, under cortical, voluntary control, consists of exhalations, like the antique exhaling pattern of laughter. As Deacon (1997: 250) puts it, "although many other primate vocalisations also involve this in-out vocalisation pattern, $[\ldots]$ it is indeed quite difficult and almost painful to speak while inhaling". As a matter of fact, the attempt to speak while inhaling produces something similar to a huge emotional jerky sobbing, as we would expect from the old breathing patterns. Thus, the assimilation of laughter to speech, their curious continuity in terms of respiratory patterns, and their common outcomes in everyday conversation and ordinary experience form a meaningful sequence, eloquent enough of a possible evolutionary path.

The continuity between nonhuman displays of joy and amusement and human emotional expression of laughter has been tested in different empirical studies. Davila Ross et al. (2009; 2010 ; 2015) compared the acoustics of tickle-induced vocalisations in infant and juvenile orangutans, gorillas, chimpanzees and bonobos with tickle-induced laughter in human infants. The results provided strong evidence of the homology between both manifestations and supported the thesis of a phylogenetic continuity. Specifically, these results allow tracing the distinctive human laughter features, such as regularity, "stable voicing and consistently egressive airflow" (Davila Ross et al. 2009: 1106), back to characteristics of shared ancestors with great apes. However, the researchers also remarked that "laughter occurring in the common ancestor of great apes and humans was limited in usage and effect" (Davila Ross et al. 2010: 193). Thus, it is not only that human laughter implies voicing and egressive airflow direction, like linguistic activity, but the fact that whereas "apes laugh primarily in the contexts of social play and tickling, laughter of humans occurs across a wide range of contexts" (Davila Ross et al. 2010: 192). Davila Ross and her team remarked that this critical 
expansion of uses and effects presumably took place in an intermediate stage of hominid evolution, maybe connected to speech-related selection, an intriguing issue that will be approached in the next sections.

Although laughter has a diversity of functions and an early evolutionary development, its connection with humour has historically brought about interesting reflections. Koestler's (1964) memorable analysis of bisociation crucially involved an explanation seeking to connect bodily reactions and mental activity. His statement about humour as an "intellectual emotion" was driven by this tension to catch the overlapping of the physical (a reflex) and the intellectual (an insight). Following this line, Koestler ventured to connect laughter and humour with its contrary, namely weeping and pain, arguing about their inverted physical patterns and their opposite emotional impact. The connection extends to the inverted pattern they show on cognitive grounds: while weeping responds to a collapsing emotion without place for reasoning and rationalising, humour and laughing, on the contrary, respond to a collapse in reasoning and rationalising, which unleashes a pleasant emotion. Complementary frames of inhibition and excitement seem to be at stake in both cases; although humour is by far the more studied case, crying has also merited interesting research in this respect (Lutz 1999). Inhibition and excitement, as opposed patterns, can also be related to the asymmetry we usually observe regarding imitation: while laughing keeps its stimulatory and imitative power during the whole adult life (think of sitcoms' canned laughs), weeping seems to blur this property during growth (see Deacon 1997: 418-420). The asymmetry is still more powerful when considered in the light of human evolution: no initial, postpartum weeping has been described in primates (Call, J., pers. comm.), although usual play and joy vocalisations are common in infant and juvenile apes and human infants. This fact suggests that the initial crying in humans (probably related to labour pains and respiratory provisions) may be a more recent outcome in evolution than the ancient, playing-like vocalisations in infants and young people, and remind us of how these antique calls have transformed themselves by merging into new physical and cognitive requirements.

\subsection{The extension of Duchenne and Non-Duchenne laughter}

Here it is throughout assumed that laughter accomplishes a huge variety of functions and develops under many different situations and provisos, varying in intensity and intention, as researchers have showed (Chafe 2007). Although we are not following that line of inquiry, the wide spectrum of social functions that laughter covers is still interesting for our argument. The critical point has probably to be fixed in the distinction between Duchenne laughter and non-Duchenne laughter, as have been described by neuroscientists and bioanthropologists. Research on facial expressions led to name "Duchenne" smile the true expression of happiness or enjoyment, after G.-B. Duchenne de Boulogne, the first researcher to identify its features in the middle of the 19th century (Duchenne 1990 [1862]; Chafe 2007: 52). Duchenne laughter has been related to playful forms of behaviour, the laughter-evoking stimuli of infants, mock-aggression or tickling (a "tickling of the mind" as Darwin said), a sort of protohumour (Provine 2000; Darwin (2012 [1899]: 805). Non-Duchenne laughter is described as strategic laughter, a learned facsimile of Duchenne laughter, like the smiles and punctuated laughs that accompany everyday conversation (Gervais \& Wilson 2005). For the purposes of this paper, smile and laughter will be assimilated, as we are only interested in the difference between spontaneous smiling and laughter, and strategic, learned and social forms of smiling and laughter accomplishing a variety of interaction goals. The first one is characterised by being emotionally-driven, involuntary (i.e. impulsive, unavoidable), while the second one is a volitional, non-emotional, articulated and socially-driven one. Research has also showed that Duchenne smile can also be faked and produced when eliciting negative 
emotions or without positive affect (Gunnery et al. 2013; Crivelli et al. 2015), showing the extent of imitative processes.

More interestingly, two partially dissociable neural pathways underlying these two different types of laughter have been identified (Wild et al. 2003). The first one comes from subcortical, limbic and brainstem areas, while the second one is a voluntary motor pattern that originates in the brain's frontal premotor areas. Wild et al. (2003: 2128-2129) have found support for this distribution in two types of facial paralysis, one leaving volitionally mimic laughter intact and the other one leaving spontaneous laughter responses to nonserious incongruities intact. As it seems, involuntary and voluntary types of laughter are then related to separate pathways for facial expressions and arise from separate neural systems, which presumably evolved in different periods: while the spontaneous, tickling type connects with old primate and ape behaviours and therefore responds to play and mirth, the volitional, more conversational type would be a more recent acquisition related to social abilities, conversational control, disparagement or derision (Gervais \& Wilson 2005).

Recent research has ventured on empirical work to explore the possible acoustic and perceptual differences between spontaneous and volitional laughter, also showing that spontaneous laughter shares features with nonhuman animal vocalizations while volitional laughter does not (Bryant \& Aktipis 2014). At any rate, two different provisos should be made, regarding this crucial distribution: on the one hand, the extension of uses and effects of spontaneous Duchenne laughter is a product of both biological and social evolution and thus, it has been transformed and modified by mirror matching systems in the brain and the development of empathy (and a theory of mind) during social cooperation (Gervais \& Wilson 2005: 415); on the other hand, volitional, motor-driven non-Duchenne laughter has achieved a degree of automaticity, as is the case with natural linguistic abilities; then, although it is strategic, learned and it can be imitated, it seems to occur largely beyond conscious control (Gervais \& Wilson 2005: 401).

For the purposes of this paper, the main interesting points of discussion are their timing of emergence and the continuity hypothesis. It seems proved that spontaneous laughter, linked to "protohumour" including rough-and-tumble play, tickling, physical mishaps or pleasant surprises, has its origins in primate social play. Ritualisation and social contagion in safe and rich multimodal and prelinguistic domains of activity may have led to extend its adaptive value, connected to a diversity of social functions by reinforcing cohesiveness and cooperation (Weisfeld 1993; Gervais \& Wilson 2005; Scott et al. 2014). Thus, the ancient nonhuman call would have gained uses and effects by joining to new behaviours, abilities and activities beyond its limited original range of play and mirth. Extended imitation has probably had a crucial role in this behavioural expansion. For Gervais \& Wilson (2005), both conversational, non-Duchenne laughter and preverbal humour would have emerged as modifications from this old, extended pattern:

This means that Duchenne laughter and protohumour would have been present in the prehuman
behavioural repertoire as various advances were made in successive species, including the
evolution of volitional oral-facial muscle control, the invention of material and cultural artefacts,
language, the evolution of a Homo sapiens-level Theory of Mind, and the emergence of fully
modern humans [...]. We propose that it is from this process that non-Duchenne laughter arose

(Gervais \& Wilson 2005: 418).

The modern, social and persuasive non-Duchenne laughter would then be connected to the mental and critical control of the social context, and probably to much more aggressive or derisive uses, due to better mind-reading abilities. The role of joint attention in evolution and the development of extended empathy (and a theory of mind), as posited by Tomasello (2008; 2014), would have contributed to the integration and modification of theses abilities. Socially 
spread forms of imitation, again, seem to be the right cue, as conversational smiling and punctuation giggles and sniggers, being actions able to be feigned, play their adaptive roles and their critical functions in social interaction. Research on behavioural alignment and synchrony (Manson et al. 2013; Finset 2014; Eaves et al. 2016) also reinforces the idea of social adaptation through multimodal signals, where those evolutionary and functionally transformed smiles and laughs find their place.

This long and complex coevolutionary process tallies with the suggested social and contextual emergence of human signing described by Dunbar (1996; 2004; 2013; 2016), when he explores how multimodal activity (grooming and variations about human haptic evolution) might have been a right environment for the transformation of laughing amidst more dynamic group activities, and thus providing a rich and safe ground for human communication to develop. As he puts it, and contrary to usual perception, everyday, common conversation would be a fair background for smiles and laughs (Dunbar 2004) and not the other way around, since smiles and laughs are forms of contact that pragmatically assure group bonding and solidarity, as well as discipline (when needed; or, alternatively, rebellion), among other functions. This seems an anthropologically appropriate account of the association between the old multimodal signals and the rather emergent articulated potentialities.

In this regard, elementary forms of humour may have emerged well before articulated languages, being displayed through incongruence and ridicule, conveyed by laughs and smiles as evolved forms of social alignment, imitation and group adaptation. As stated above, Scott-Phillips' (2014) ostensive-inferential model of integrating multimodality and intentions, applied to the evolution of the social mind and crucially relying on the expression and recognition of intentions (and then, in the development of a theory of mind), represents a consistent pragmatically-based framework for our argument, i.e. the attempt to explain the presumably early expansion and diversification of laughter and humour. As for cognition and articulated language, positive co-optation may also have been the rule:

In this scenario language and humour would no doubt have coevolved to some extent, with language and speakers becoming more adept at eliciting laughter and the laughter mechanism becoming more susceptible to conceptual triggering. But [...] only the original properties of Duchenne laughter would have allowed it to be evolutionarily harnessed by language. Only insofar as language was able to conform to the structure of the already established elicitor of laughter could it trigger the laughter response.

(Gervais \& Wilson 2005: 419)

And yet the cognitive aspects of humour seem to be the most difficult to explore on natural basis. While it has been quite well established that the extension of uses and effects of laughter may have contributed to their actual multifunctionality in social contexts, the emergence of articulated languages, even if it happened in parallel to multimodal activity, poses new problems of coherence and comprehension. As Gervais \& Wilson point out (2005: 420), the new mental abilities had to match "the potential of language to represent nonserious social incongruity and the affective properties of laughter that constituted its functional potential", in order for us to understand the "variety of forms and functions that characterise laughter today". Then, in the following section, we approach the social and the cognitive (or rather semiotic) aspects presumably involved in the emergence of verbal humour. 


\section{Social and cognitive issues}

\subsection{Human laughter helps define social groups}

Current research usually assumes the beneficial and cooperative functions of laughter (and humour) in the course of human evolution, its glue character to creating bonds and maintaining relationships (Deacon 1997; Gervais \& Wilson 2005; Dunbar 2013; Scott et al. 2014). But its non-affiliative, aggressive or critical side has been less explored and less theorised in this respect. An interesting exception is Billig (2005), who considers both the disciplinary and the rebellious sides of humour and laughter in social relationships. Rebellion and discipline are, of course, opposed and complementary sides of social regulations. Billig refuses the current trend of considering mainly the beneficial (so called "positive") aspects of humour. His research stems from social psychology, and it aims to present ridicule and embarrassment as the less explored effects and consequences that humour and laughter trigger in social interaction. Instead of focusing in abstract, non-engaged definitions of humour as incongruity or frame collapse, Billig insists on the links humour and laughter weave with social differences, rules and interdictions. Thus, two different sides of the process emerge to explain ridicule and embarrassment: their active, sanction-like potential, conveyed by disciplinary mocking, where the butt of the jokes or the target of the pranks have a lesson to learn; and their opposite, overtly critical counterpart conveyed by rebellious mocking, where somebody reacts again an oppressive or discouraging rule, by putting it into question. Both complementary sides described by Billig depart from the positive mode of humour commented in the literature, which emphasises the well-being, solidarity bonds and affective properties. Critical arguments about the social uses of humour, its value to discriminate, to build and reinforce social and cultural stereotypes, to criticise social or ethnic groups, have also been profitably put under scrutiny in the sociological literature (Davies 1998; Kuipers 2015).

Billig's (2005) research leads us to speculate about how humour and laughter can be related to the origins of social rules. Discipline and rebellion are the true marks of social organisation. As Billig argues, both sides are present in the making of ridicule. Both participate in the construction and reconstruction of sanctions. And yet, at any rate, it will be a mistake to concentrate only in the disciplinary (or the rebellious) side, setting aside the bonding effects of humour and laughing. Discourse analysis has fruitfully shown how humour effectively works both on bonding (by creating solidarity) as well as on discipline (or its contrary, rebellion; see among others Holmes \& Stubbe 2015). The bonding dimension builds the ingroup domain, while disciplinary and rebellious attitudes work on an outgroup basis, signalling actual or potential opponents or rivals. Both dimensions, then (i.e. the ingroup functions of solidarity and security and the outgroup functions of sanctioning divergence or abuse) appear strictly complementary, and seem necessary for humour and laughter to emerge (cf. Martin 2007: 210-225). Then, it makes sense to hold that both sanction and solidarity are at the origins of social rules. Discipline or rebellion, and their opposite, bond and solidarity, mark what social rules are and how they work. Laughter should have played a role in informal, prelinguistic environment in this sense, as it still does today in pair with linguistic activity. The extension of uses and effects of laughter we have been considering here would be mainly related to these emerging functions.

Lastly, one should be tempted to connect the ancient call of laughter assuming these new rich and social functions to the complementary (and recessive) reflex of blushing, as described by Darwin (2012 [1899]), the bodily sign for embarrassment, which may be associated to the origins of a developed empathy and a theory of mind. This is a step that Billig, despite his interest in embarrassment and social rules, does not overtly take (although 
he refers to it; see Billig 2005: 221), but it is a connection that could be interesting to explore, since both laughter (through ridicule) and blushing (through shame) are connected to forms of embarrassment that more or less manifest the social order, how it works and what its right settings are. As a matter of fact, both laughter and blushing are ancient bodily marks crucially related to the evolution of the social mind, and at the end of the nineteenth century both reflexes captured the interest of Darwin (2012 [1899]), as embodied emotions.

\subsection{Humour feeds verbal communication}

Conversation analysis has shown the pervasiveness of humour and jokes in everyday, common interaction and their polyphonic functions (Norrick 1993; Priego-Valverde 2003). Wordplay is not an exception in this context but the normal case, as the research shows. Speakers use everyday language in an easy-going way and a relaxed attitude, ready to twist meanings, play with similar forms or retort with non-perfectly coherent answers. Absolute logic does not command common, everyday interaction in its minor, routine-like details. The attachment of humour and play to everyday conversational interaction is a solid and powerful condition. Conversation, under this view, should be considered as a basic and substantial form of interaction, where multimodality still plays a determining role. That's why adaptation and cooperation have been described as important features of conversation from an evolutionary point of view (Dunbar 2004; Manson et al. 2013), even when joking is considered (Dunbar 2016). In this sense, linguistic activity is inescapably social (there are no individual languages), a property that has also been attributed to humour and laughing (Gervais \& Wilson 2005).

Even in its common manifestations, humour is related to language by a multiplicity of procedures (Nash 1985). And yet it is not only the case that humour possibilities have permeated the whole structure of language and hold connections with creativity and expression, but the fact that humour potential has been developed into different literary, imaginative genres over the course of history and literary history. This should be viewed as a very strange situation, with few equivalents in other domains: an ancient sign that adheres to the rather new, symbolic (i.e. articulated) order of expression, and rises to elaborated cognitive forms that mutate and adapt (as literature had also done) into new, accepted forms of play, mirth and criticism; not to mention jokes, the old humorous genre by excellence, a vehicle for transmission of cultural contents with many familiar links with narrativity (Attardo 2001).

To be sure, humour plays an interesting role in a fair variety of semiotic and cultural domains. Deacon (1997: 420) argued that the connection between laughter and humour could be "a side effect of the adaptation for symbol learning". A definitory fact of symbolic activity is that interpretation always involves more than understanding what is said. In this respect, interpreting jokes entails "simultaneously to entertain inconsistent alternative perspectives extrapolated from the same initial context" (Deacon 1997: 420). And it is a fact that, in everyday communication, we must choose, from a chaotic and excessive ground, which figures fit our purposes, and so, as Bergson (1900) said, we are always close to discovering the mechanical (i.e. the unintended) embedded in the animate (i.e. the purposeful). From Koestler (1964) on, we know that insight and surprise are critical components of humour. In Deacon's argument, insight and surprise crucially "implicate prefrontal functions that enable mutually exclusive associations to be juxtaposed"; and perhaps the unleashing of laughter, "like the sudden disinhibition of a suppressed automatic response, reflects the disengaging of prefrontal control" (Deacon 1997: 421).

The question can be rephrased as follows: The wide connectivity opened by the emergence of articulated languages and the spread of full symbolic activity entails 
interpretive complexity. Symbolic meanings do not boil down to mere exchanges but involve a work of selection (and substitution) and combination (and contextualisation). From this background of associative order and unbounded connectivity, our words and social meanings emerge and take shape. When inordinate associations suddenly emerge beyond our monitoring, cortical control yields ground to the emotional, reflex response of laughter. This may be an acceptable statement to grasp the coevolution of cognition, humour, and its ancient and partially convergent embodied sign, laughter.

It is our contention that, when the expanded human symbolic abilities came into scene, the previous social potential of humour and laughter, fuelled by incongruity and ridicule, was presumably readjusted (rewired, rerouted), in order to signal outbreaks of unlimited connectivity at the cognitive level. This early attachment would have sustained and fed new associations in turn, and, in a typical recursive way, would have produced and recreated the rich combinations we currently observe across a diversity of semiotic and cultural genres where humour finds its place. If language and reason allow us to have some distance from sudden emotions, the stereotypical reflex brought us back to the breeding ground of multiple associations and unlimited connectivity, always latent and necessary for cognition.

\subsection{Connectivity by means of contact and similitude}

Extended brain connectivity joined to long-distance neural associations have been usually deemed particular properties of the homo sapiens' cognitive evolution, sometimes referred to as hyperconnectivity (Edelman 2005; Balari \& Lorenzo 2013). The interesting question for our argument is that connectivity is grounded on interwoven relationships that assure unbounded interpretation, this being the matrix of symbolic activity. As cognitive semiotics maintains (Schilhab et al. 2012), mental activity can be described in terms of signs, of full semiotic complex interactions. This approach in terms of semiotic relationships has a long history: it can be retraced to ancient rhetorical patterns, where verbal and nonverbal associations had been fruitfully explored in different pragmatic and persuasive settings. The tradition of association types continues to John Locke (1632-1704) and David Hume (17111776), and was rediscovered by modern scholars as a solid background of cultural meanings (Leach 1976). We usually say that there are associations in the code (by similitude) as opposed to associations in the message (by contact), and, moreover, we can build relationships from the code to the message (wording; verbal) as well as the opposite, from the message to the code (decoding; conceptual). Similitude and contact, respectively, are the foundation of common tropes, metaphor and metonymy; wording and decoding, likewise, were the foundation of figures, verbal and nonverbal, in the rhetorical parlance. As Attardo (1994) notes, Cicero (106 BC-46 BC) was probably the first scholar to locate humour and jokes (facetiae) among those types of associations. Probably unaware of the Ciceronian division between verbal and nonverbal jokes (as well as those built by similitude and those built by contact), Freud (1960 [1905]) engaged himself in a similar but also productive multiclassification of humour and jokes, which allowed tracing them back to dreaming activity, and thus indirectly showing the relevance of the ancient rhetorical (or semiotic) pattern.

Thus, contact and similitude, as well as verbal and referential (or conceptual) associations, have been reported as the framework of unconscious activity, and the background of verbal and nonverbal conscious symbolic work. Here is where we find humour as the unleashing of this fruitful connectivity. Contact and similitude, as well as metaphor and metonymy (Trim 2007), are the breeding ground of symbolic activity at cognitive and linguistic levels. On the one hand, contact or contiguity are the base for indexical solutions; on the other hand, similitude or resemblance are the foundation of iconic relationships, in 
semiotic terms (Viana 2015). Notice that humour pulls out its automatic, reflex bisociations (to use Koestler's term; Koestler, 1964: 35-36) from resemblances and contiguities, both verbal and nonverbal. The resulting, numberless variations in humorous typology ultimately stem from this particular attachment to the quadripartite matrix of contact and similitude, verbal and nonverbal, and are fuelled by it, as the early semiotic study of Milner (1972) usefully showed. In parallel to dreaming activity or figurative thinking, humour works on the spontaneous region of unbounded relationships, usually seen as the background of more conscious, methodical and purposeful cognitive operations. Considering this rich and productive process of symbolic associations, these arguments bring back humour to the origins of the extended connectivity that distinguishes our species, and to the way the old signs of play, social discrimination, ridicule and incongruity may have been readapted to match the increase of cortical control over conscious cognitive production, by signalling spontaneous, unrestrained relations. The connection between unlimited associations in the symbolic domain (i.e. incongruity or bisociation) and the ancient reflex of laughter speaks in favour of the fact that we are in front of very old evolutionary processes presumably related, as Deacon (1997: 420-421) suggested, to the development of full levels of symbolic activity characterised by unbounded interpretation.

\section{Humour and laughter point the way to the imaginative function of the ancient mind}

The idea of vestiges (lat. vestigium, footprint) has been very powerful in natural sciences (Donald 2002). It is of use today in astrophysics, where galaxies are measured by their distance in time from an original point. Vestiges, of course, are fully operative in many scholarly domains, and we should esteem their actual power in addition to their history and their primeval functions. In this paper, it is argued that humour and laughter may be interestingly regarded, from the point of view of their evolutionary history, as vestiges of hominisation processes. Indeed, some effort has been devoted to attributing a place to humour in the evolutionary stages that brought forth the human mind, by asserting its survival properties under a generalised framework that assumes the rational nature of cognitive activity and its computer-like performance. Consequently, it is argued, humour as a surviving device aptly matches these rationality-oriented properties (Hurley et al. 2011). In this paper we attempt to depart from a narrow-minded version of rationality and look for a complementary, more comprehensive account of the origins of the mind, by setting us in a cognitive and pragmatic perspective (Donald 1991; Mithen 1996).

In this regard, we can fruitfully use the amount of research that has been produced about humour, literature and creativity. Literature is part of our rationality, as humour is; both represent the qualities of order and meaning, acquired by different methods than those used in algorithmic, controlled cognitive procedures. In Bateson's (1972; 1979) early cognitive semiotics, it is remarked that dreaming, original myth-telling, social play and fantasy might have bolstered human evolution and may be seen as archaic ways to convey dimensions that we explore today under artistic forms such as dance, music or theatre. More specifically, play and fantasy should have had an innovative role in the cognitive and pragmatic development of the human mind. Thus, it has been argued that our persistent use of a moderated creativity during the whole adult life is a juvenile remnant of human evolution that has indeed lingered on over the years, an intriguing feature without correspondence in nonhuman mammal environment (Montagu 1981). Thus, Bateson (1985) did not hesitate to include joking and humour among those early capacities that brought forth a new flexibility for human thought. Dreaming is still with us as a necessary built-in process, required for (and complementary to) 
our everyday cognitive abilities (States 1993). Storytelling has developed in the multiple forms literature and art have to evoke meanings, values and experiences. And, as we have seen, humour has clung to elaborate cognitive processes and has spread over a diversity of domains, keeping its paradoxical character of signalling the unlimited associative capacity.

There has also been interesting research aligning humour with the paradoxes and uncertainties of literature, without overlooking the evolutionary origins (Gutwirth 1993; Berger 2014). From anthropology, the idea of the social celebration of absurdities and the emergence of comic rituals has also been explored, as well as the proximity of humour with metaphor and creativity (Douglas 1975b). Even from the field of literary criticism, the idea that verbal invention (i.e. puns and wordplay) unleashes humour, being at the same time one of the original pillars of literary production, has merited a certain attention (Culler 1988). Koestler (1964) built an interesting comparative relation between three different cognitive fields where creativity was at stake, namely science, humour and art, in a research that can subsume the efforts to offering a wide version of rationality, where non-algorithmic, unlimited and open associative procedures are welcome.

For cognitive semiotics, the mind is a construct that constructs itself by doing things (Danesi 1993; Donald 2002; Schilhab et al. 2012). Among its forming properties, creative imagination has been considered a fundamental one. Figurative thinking was essential for the birth of cults and rituals, at the beginning of homo sapiens, then giving way to ancient religions. The faces we still see in the clouds are the best vestiges of humanisation (Guthrie 1993), a process that led to project in nature our own experience and human body features, by means of imagining animated properties. Dreaming, the discovery of objects proper to us (i.e. things), wide naming processes, (un)purposeful projections and fears, all that array of activity constitutes the original material of figurative work, the cradle of thinking. Participation is also a word that has been used to describe this early but still-in-use stage of the mind (Barfield 1988), where the universe is not yet something "out there" but a consistent continuity between our thoughts, observed processes and fantasies. A mess of indexicality and iconicity, of contamination and likeness, where language and pragmatic action were not missing, would be the right background for a participative scenario. We should not elude the proper linguistic contribution to these issues, because we know that ritual, magic spells and sorcery were at the back of early uses of words and concepts. In its true core, language is a sediment of anthropomorphisms, a network of indexical and iconic projections (Cassirer 1955). Figurativeness is the outcome of this associative work, and from this context of extended connectivity we tentatively assume that humour found its place as a powerful signal of the outburst of unlimited associations, largely connected to affiliative as well as disciplinary social functions.

Writing about art and emotion, Cassirer (1944: 150) pointed out that comic art possessed "in the highest degree that faculty shared by all art, sympathetic vision". We should read the phrase "sympathetic vision" along the lines of participation and enchantment. As creditable defenders of positive and beneficial humour maintain, insisting in the creative and rich power of bisociation, humour aligns itself with illusion, fantasy, and emotive participation (Fry 1963; Berger 2014). It reminds us of this world upside down, replete of mixed properties where horses master rhetorical devices, partition walls start flying or ravens have three legs. In a parallel way to emotive participation, humour and jokes do not distinguish between inner and outer properties, space and time as a priori forms, or well established linguistic paradigms. Playing with those categories, humour and jokes seem to evoke the old property of utterances to lure and captivate by means of fantastic and imaginative classifications, and this is what participation is about, that is its proper parlance. As far as figurative thinking had apparently been the original form the human mind embraced in order to build meaning by 
means of participative plots and projections, humour as a way to underscore the domain of boundless associations may have fed this scenario.

A nice reasoning by Kant (1914 [1790]) would help us strengthen our case. Besides his well-known and often quoted assertion that laughter "is an affection arising from the sudden transformation of a strained expectation into nothing," Kant (1914 [1790]: 222) affirmed that always "there must be something absurd (in which the Understanding, therefore, can find no satisfaction)." The German philosopher resorted to non-solved incongruity in order to align humour with spotless incomprehension. He overall contends that the act of understanding lies at the opposite pole of humour and laughter. Thus, he grouped together "music and that which excites laughter" (as two different kinds of play with aesthetical ideas), "through which ultimately nothing is thought" (Kant 1914 [1790]: 223). Music and humour, then, would be pleasures that may be enjoyed without content. Coming from a sheer rationalist, this statement merits to be taken into consideration. If we pay attention to the contrast and oppositeness between humour and understanding, the former may be more easily ascribed to the functions of the primitive mind. Its alliance with emotions, as is also the case with music (and singing), lets us classify them as early forms of order and social significance. We could say that both are ways of understanding without understanding, ways of conveying social meanings that eschew rational content. Following this trend of reasoning, we could also regard humour as a direct challenge to the famous first sentence of Aristotle's Metaphysics: "All men naturally desire knowledge" (Aristotle 1933-1989: 1980a). Humour both celebrates and questions Aristotle's statement. And that is understandable from an evolutionary point of view, if humour is a signal of the haul of evolution of human language and mind.

Our last issue deals with embodiment. As we have argued, laughter presumably preceded articulated linguistic activity, although its functions have kept expanding for thousands of years. Humour and its partially convergent evolutionary counterpart, laughter, are bodily manifestations of the "sympathetic" mode of the mind, to say it à la Cassirer. Thus, the issue of embodiment is not a minor one, and this connection has amazed scholars from the very beginning of humour inquiries. Even Kant argued that laughter as bodily manifestation ("the movement of the organs of the body") was caused by the nonunderstandable and yet enjoyable transformation that humour consists of ("the sudden transposition of the mind", Kant 1914 [1790]: 226). But the embodiment that humour and laughter exhibit carries its own evolutionary history. Douglas (1975a), while exploring the playful character of laughter already present in nonhuman mammal environments, considered its bodily basis. For human contexts, she postulated a rule of coherence between humour, body and the social order, involving these three levels to get the right, mirthful inversion that humour implies (for a pragmatic approach to the coherence rule, see Viana 2006). As noted above, this connection may be viewed as a piece of evidence of its ancient origins, as the laughter reflex was imprinted in the old physical networks that compound body and thought, presumably creating the most conspicuous and intriguing feature of the participative mind.

\section{Conclusion}

In this paper, humour and laughter have been presented as vestiges of the evolution of human language and mind. Firstly, it has been argued that multimodality (through gestural, facial and vocal signs) presumably preceded in evolutionary history articulated languages. Secondly, the question of the continuity between human laughter and nonhuman mammal vocalisations has been consequently raised. It has been maintained that human laughter shows a clear continuity with nonhuman mammal vocal expressions, and we have inquired about the issue of bipedalism and how it should have influenced the development of 
specifically human laughter features, from the point of view of breathing possibilities as well as those of the arrival of new multimodal human signs.

The contentions of this paper include that the proposed continuity between nonhuman mammal vocalisations and human laughter had two meaningful turning points, from which their similitudes depart and continuity transforms itself. Firstly, we should consider the extension of uses and effects of laughter via neural imitation procedures, social alignment, and the development of a theory of mind, probably during an evolutionary intermediate period before the appearance of homo sapiens. This extension of uses and effects includes the divide between Duchenne and non-Duchenne laughter and, presumably, the emergence of preverbal humour enabled by ridicule and incongruity. Secondly, we should take into account the developmental extension favoured by the late and impressive cognitive acceleration brought forth by the emergence of articulated languages. In this new context, both the ancient reflex and the alleged forms of preverbal humour had presumably been readapted to match the new demands of symbolic thinking.

Thus, we tentatively hypothesise that this adjustment happened under two interesting and complementary conditions: a) the polarity of social functions, by the increasing conjoined work of sanction and solidarity; and b) the extended connectivity that distinguishes our species at the cognitive level, working on figurative (metaphorical and metonymical) basis, sustaining from its inception the imaginative functions of the primitive mind. Then, when the expanded human symbolic abilities came into scene, the previous social potential of humour and laughter, fuelled by incongruity and ridicule, may have been rearranged to signal outbreaks of unlimited associations, largely related to affiliative as well as disciplinary social functions, and still eliciting an unintended bodily response.

As we have seen, both humour and laughter diversified their functions in the course of evolution, but they crucially readapted to figurativeness, as an emergent property of the mind, by underscoring the spontaneous, unrestrained associative capacity, at the time when full levels of symbolic activity unfolded, characterised by unbounded interpretation. If this was so, then humour, fuelled by language, may be seen as an embodied sign for the imaginative function of the mind, and one particularly attuned to the improvement of human social and cognitive abilities. Nevertheless, we are aware that the hypothesis championed here has to be provisionally taken, until converging evidence from other sources can be found, in order to achieve a sound result on the evolutionary paths of laughter and humour.

\section{References}

Altenmüller, E., Schmidt, S. \& Zimmermann, E. (2013). Evolution of Emotional Communication: From Sounds in Nonhuman Mammals to Speech and Music in Man. Oxford: Oxford University Press.

Aristotle (1933-1989). 'Metaphysics', in Tredennick, H. (ed.), Aristotle, vols. 17-18, Cambridge MA: Harvard University Press. http://data.perseus.org/citations/urn:cts:greekLit:tlg0086.tlg025.perseus-eng1:1.980a

Attardo, S. (1994). Linguistic Theories of Humor. Berlin: Mouton de Gruyter.

Attardo, S. (2001). Humorous Texts: A Semantic and Pragmatic Analysis. Berlin: Mouton de Gruyter.

Bachorowski, J.-A. \& Owren, M. J. (2001). 'Not all laughs are alike: Voiced but not unvoiced laughter readily elicits positive affect'. Psychological Science 12, pp. 252-257.

Balari, S. \& Lorenzo, G. (2013). Computational Phenotypes. Oxford: Oxford University Press.

Barbieri, M. (2010). 'On the origin of language'. Biosemiotics 3, pp. 201-223. 
Barfield, O. (1988 [1965]). Saving the Appearances: a Study in Idolatry. Connecticut: Wesleyan University Press.

Bateson, G. (1972). Steps to an Ecology of Mind. San Francisco: Chandler.

Bateson, G. (1979). Mind and Nature. London: Wildwood House.

Bateson, G. (1985 [1955]). 'A theory of play and fantasy', in Innis, R. E. (ed.), Semiotics, London: Hutchinson, pp. 131-144.

Berger, P. L. (2014). Redeeming Laughter: The Comic Dimension of Human Experience. Berlin: Mouton de Gruyter.

Bergson, H. (1900). Le rire: essai sur la signification du comique. Paris: Félix Alcan.

Billig, M. (2005). Laughter and Ridicule. London: Sage.

Bryant, G. A. \& Aktipis, C. A. (2014). 'The animal nature of spontaneous human laughter'. Evolution and Human Behavior 35, pp. 327-335.

Cassirer, E. (1944). An Essay on Man. New Haven: Yale University Press.

Cassirer, E. (1955). The Philosophy of Symbolic Forms, vol. I, Language. New Haven: Yale University Press.

Chafe, W. (2007). The Importance of not Being Earnest. Amsterdam: John Benjamins.

Corballis, M. C. (2003). From Hand to Mouth: The Origins of Language. Princeton: Princeton University Press.

Crivelli, C., Carrera, P. \& Fernández-Dols, J.-M. (2015). 'Are smiles a sign of happiness? Spontaneous expressions in judo winners'. Evolution and Human Behavior 36 (1), pp. 52-58, http://dx.doi.org/10.1016/j.evolhumbehav.2014.08.009.

Culler, J. (1988). On Puns: The Foundation of Letters. Oxford: Blackwell.

Danesi, M. (1993). Vico, Metaphor, and the Origin of Language. Bloomington: Indiana University Press.

Darwin, C. (2012 [1899]). The Expression of the Emotions in Man and Animals. New York: Appleton and Company. http://www.gutenberg.org/files/1227/1227-h/1227-h.htm

Davies, C. (1998). Jokes and their Relation to Society. Berlin: Mouton de Gruyter.

Davila Ross, M., Owren, M. J. \& Zimmermann E. (2009). 'Reconstructing the evolution of laughter in great apes and humans'. Current Biology 19, pp. 1106-1111.

Davila Ross, M., Owren, M. J. \& Zimmermann E. (2010). 'The evolution of laughter in great apes and humans'. Communicative and Integrative Biology 3 (2), pp. 191-194.

Davila Ross, M., Goncalo, J., Osborne, J. \& Bard, K. A. (2015). 'Chimpanzees (pan troglodytes) produce the same type of "laugh faces" when they emit laughter and when they are silent'. PLoS One 10 (6), http://dx.doi.org/10.1371/journal.pone.0127337.

Deacon, T. (1992). 'The neural circuitry underlying primate calls and human language', in Wind, J., Chiarelli, B. \& Bichakjian, B. (eds.), Language Origins: A Multidisciplinary Approach, Dordrecht: Springer, pp. 121-162.

Deacon, T. (1997). The Symbolic Species. New York: W. W. Norton.

Donald, M. (1991). Origins of the Modern Mind. Cambridge MA: Harvard University Press.

Donald, M. (2002). A Mind so Rare. New York: W. W. Norton.

Douglas, M. (1975a). 'Do dogs laugh? A cross-cultural approach to body symbolism', in Implicit Meanings, London: Routledge, pp. 83-89.

Douglas, M. (1975b). “Jokes", in Implicit Meanings, London: Routledge, pp. 90-114.

Duchenne de Boulogne, G.-B. (1990 [1862]). The Mechanisms of Human Facial Expression. New York: Cambridge University Press.

Dunbar, R. I. M. (1996). Grooming, Gossip and the Evolution of Language. Cambridge, MA: Harvard University Press.

Dunbar, R. I. M. (2004). The Human Story. London: Faber \& Faber.

Dunbar, R. I. M. (2013). 'Bridging the bonding gap: the transition from primates to humans'. Philosophical Transactions of the Royal Society B 367, pp. 1837-1846. 
Dunbar, R. I. M. (2016). 'Group size, vocal grooming and the origins of language'. Psychonomic Bulletin and Review, doi:10.3758/s13423-016-1122-6.

Dunbar, R. I. M. \& Barrett, L. (2007). The Oxford Handbook of Evolutionary Psychology. Oxford: Oxford University Press.

Eaves, D. L., Behmer Jr., L. P. \& Vogt, S. (2016). 'EEG and behavioural correlates of different forms of motor imagery during action observation in rhythmical actions'. Brain and Cognition 106, pp. 90-103.

Edelman, G. M. (2005). Wider than the Sky: View of Consciousness. Harmondsworth: Penguin.

Finset, A. (2014). 'Talk-in-interaction and neuropsychological processes'. Scandinavian Journal of Psychology 55 (3), pp. 212-218.

Fitch, W. T. (2010). The Evolution of Language. New York: Cambridge University Press.

Freud, S. (1960 [1905]). Jokes and their Relation to the Unconscious. New York: W. W. Norton.

Fry, W. F. (1963). Sweet Madness: A Study of Humor. Palo Alto: Pacific Books.

Gervais, M. \& Wilson, D. S. (2005). 'The evolution and functions of laughter and humour: a synthetic approach'. Quarterly Review of Biology 80, pp. 395-430.

Gunnery, S. D., Hall, J. A. \& Ruben, Mollie A. (2013): 'The deliberate Duchenne smile: individual differences in expressive control'. Journal of Nonverbal Behavior 37 (1), pp. 29-41.

Guthrie, S. (1993). Faces in the Clouds: A New Theory of Religion. Oxford: Oxford University Press.

Gutwirth, M. (1993). Laughing Matter: an Essay on the Comic. Ithaca: Cornell University Press.

Heine, B. \& Kuteva, T. (2007). The Genesis of Grammar. Oxford: Oxford University Press.

Holmes, J. \& Stubbe, M. (2014). Power and Politeness in the Workplace. London: Routledge.

Hurley, M. H., Dennett, D. C. \& Adams, R. B. Jr. (2011). Inside Jokes: Using Humor to Reverse-Engineer the Mind. Cambridge, MA: The MIT Press.

Kant, I. (1914 [1790]). Critique of Judgment. London: Macmillan. http://oll.libertyfund.org/titles/kant-the-critique-of-judgement.

Koestler, A. (1964). The Act of Creation. New York: Macmillan.

Kuipers, G. (2015). Good Humor, Bad Taste: A Sociology of the Joke. Berlin: Mouton de Gruyter.

Larson, R. K., Déprez, V \& Yamakido, H. (2010). The Evolution of Human Language: Biolinguistic Perspectives. New York: Cambridge University Press.

Leach, E. R. (1976). Culture and Communication. Cambridge: Cambridge University Press.

Lutz, T. (1999). Crying. New York: W. W. Norton.

Manson, J. H., Bryant, G. A., Gervais, M. M. \& Kline, M. A. (2013). 'Convergence of speech rate in conversation predicts cooperation'. Evolution and Human Behavior 34, pp. 419426.

Martin, R. A. (2007). The Psychology of Humor: An Integrative Approach. Burlington: Elsevier.

Milner, G. B. (1972). 'Homo ridens: towards a semiotic theory of humour and laughter'. Semiotica 5, pp. 1-130.

Mithen, S. R. (1996). The Prehistory of the Mind. London: Thams and Hudson.

Mithen, S. R. (2005). The Singing Neanderthals: The Origins of Music, Language, Mind and Body. London: Weidenfeld \& Nicolson.

Montagu, A. (1981). Growing Young. New York: McGraw Hill.

Nash, W. (1985). The Language of Humour. London: Longman. 
Norrick, N. R. (1993). Conversational Joking: Humor in Everyday Talk. Bloomington: Indiana University Press.

Priego-Valverde, B. (2003). L'humour dans la conversation familière: description et analyse linguistiques. Paris: L'Harmattan.

Provine, R. (2000). Laughter: A Scientific Investigation. New York: Viking.

Provine, R. (2016). 'Laughter as an approach to vocal evolution. The bipedal theory'. Psychonomic Bulletin and Review, doi:10.3758/s13423-016-1089-3.

Ramachandran, V. S. (1998). 'The neurology and evolution of humour, laughter and smiling: the false alarm theory'. Medical Hypothesis 51, pp. 351-354.

Schilhab, T., Stjernfelt, F. \& Deacon, T. (2012). The Symbolic Species Evolved. New York: Springer.

Scott, S., Lavan, N., Chen, S. \& McGettigan C. (2014). 'The social life of laughter'. Trends in Cognitive Science 18 (12), pp. 618-620.

Scott-Phillips, T. (2014). Speaking Our Minds. Basingstoke: Palgrave Macmillan.

States, B. O. (1993). Dreaming and Storytelling. Ithaca: Cornell University Press.

Tomasello, M. (2008). Origins of Human Communication. Cambridge, MA: The MIT Press.

Tomasello, M. (2014). A Natural History of Human Thinking. Cambridge MA: Harvard University Press.

Trim, R. (2007). Metaphor Networks: The Comparative Evolution of Figurative Language. New York: Macmillan.

Turner, M. (1997): The Literary Mind: The Origins of Thought and Language. Oxford: Oxford University Press.

Turner, M. (2006): The Artful Mind: Cognitive Science and the Riddle of Human Creativity. Oxford: Oxford University Press.

Viana, A. (2006). 'Flipping situations and ending plots'. Círculo de Lingüística Aplicada a la Comunicación 27, http://pendientedemigracion.ucm.es/info/circulo/no27/viana.pdf.

Viana, A. (2015). Tempesta de signes. Lleida: Universitat de Lleida.

Weisfeld, G. E. (1993). 'The adaptive value of humour and laughter'. Ethnology and Social Biology 14, pp. 141-169.

Wild, B., Rodden, F. A., Grodd, W. \& Ruch, W. (2003). 'Neural correlates of laughter and humour'. Brain 126, pp. 2121-2138.

Wildgen, W. (2004). The Evolution of Language. Amsterdam: John Benjamins.

Zlatev, J. (2012). 'Cognitive semiotics: an emerging field for the transdisciplinary study of meaning'. The Public Journal of Semiotics IV (1), pp. 2-24. 